\title{
Association of Haplotypes in the CXCR2 Gene with Periodontitis in a Brazilian Population
}

\author{
Aline C. Viana, ${ }^{1}$ Yeon J. Kim, ${ }^{1}$ Karen M.C. Curtis, ${ }^{2}$ Rivelto Renzi, ${ }^{2}$ Silvana R.P. Orrico, \\ Joni A. Cirelli, and Raquel M. Scarel-Caminaga ${ }^{2}$
}

CXCR-2 is a receptor of interleukin-8, which is involved in acute and chronic inflammatory processes. Polymorphisms in the CXCR2 gene have been associated with chronic inflammatory conditions. The aim of this study was to investigate whether the $+785(\mathrm{C} / \mathrm{T}),+1208(\mathrm{~T} / \mathrm{C})$, and $+1440(\mathrm{G} / \mathrm{A})$ single-nucleotide polymorphisms (SNPs) in the CXCR2 gene, as well as their haplotypes, are associated with susceptibility to periodontitis in Brazilians. DNA was extracted from the buccal epithelial cells of 487 individuals (control=215; periodontitis =272). The SNPs were investigated using the sequence-specific primer-polymerase chain reaction method. Associations between the polymorphisms and subject phenotypes were analyzed using the chi-squared statistical test, followed by univariate and multivariate logistic regression modeling. Haplotypes were reconstructed using the expectation-maximization algorithm, and differences in haplotype distribution between the groups were analyzed to estimate genetic susceptibility for periodontitis development. Univariate and multivariate analysis revealed that age, skin color, and smoking status were associated with periodontitis. The +1440 GG genotype was shown to be protective against periodontitis in both univariate and multivariate analysis (odds ratio $[\mathrm{OR}]_{\text {adjusted }}=0.42 ; 95 \%$ confidence interval $[\mathrm{CI}]=0.19,0.96$ ). A similar relevant result for the +1440 GG was obtained in an alternative analysis considering a subgroup containing only white nonsmokers $(\mathrm{OR}=0.37 ; 95 \% \mathrm{CI}=0.15,0.92)$. White nonsmokers with the CTG/TCG haplotype appeared to be genetically protected against the development of periodontitis $(\mathrm{OR}=0.29 ; 95 \% \mathrm{CI}=0.09,0.89)$, while those carrying the CTG/TCA haplotype were more susceptible to the development of periodontitis $(\mathrm{OR}=2.08 ; 95 \% \mathrm{CI}=1.24$, 3.51). In conclusion, the $+1440 \mathrm{SNP}$ and some haplotypes are associated with periodontitis in Brazilian individuals.

\section{Introduction}

$\mathbf{P}$ ERIODONTITIS IS A multifactorial disease that is primarily caused by bacterial stimuli (Hafajee and Socransky, 1994) and has a progression closely linked to the host immunoinflammatory response (Yoshie et al., 2007). The inflammatory process in periodontitis is one of the factors responsible for tissue damage, resulting in periodontal pocket formation and destruction of the periodontal ligament and adjacent support bone (Susin et al., 2005; Van Dyke, 2007). Previous studies have reported the importance of specific cytokines, such as interleukin 1 (IL-1) (Massada et al., 1990), IL-2 (Ozawa et al., 2003), IL-4 (Yamazaki et al., 1994), IL-6 (Irwin and Myrillas, 1998), and IL-10 (Yamazaki et al., 1997), in this process.

IL-8, a member of the CXC chemokine family, is primarily responsible for the activation and migration of neutrophils into tissue from peripheral blood (Strieter, 2002). The term CXC is derived from the chemokine structure, which includes two cysteines and one intervening amino acid (Mukaida, 2003). IL-8 is also involved in the initiation and amplification of acute inflammatory reactions and in the chronic inflammatory process (Campa et al., 2005). There are two specific receptors for IL-8, CXCR-1, and CXCR-2 that are responsible for mediating its cellular activities. The amino acid sequences of CXCR-1 and CXCR-2 are 77\% identical (Murphy and Tiffany, 1991), and these two receptors are encoded by two single-copy genes located on chromosome 2q34-35 (Morris et al., 1992). CXCR-2 binds IL-8 and other CXC chemokines with high affinity, whereas CXCR-1 binds only IL-8 (Baggiolini, 1998).

The CXCR2 gene (GenBank accession number M99412) is composed of three exons, and the open reading frame is entirely encoded in the third exon (Sprenger et al., 1994). 
Some single-nucleotide polymorphisms (SNPs) in the CXCR2 gene have been reported: $+785(\mathrm{C} / \mathrm{T})$ is located in exon 3 (refSNP ID: rs2230054) (reference sequence number from the NCBI's Entrez system) and +1208(T/C) rs1126579 and $+1440(\mathrm{G} / \mathrm{A})$ rs 1126580 are in the $3^{\prime}$ untranslated region of exon 3 (Renzoni et al., 2000).

Associations of these SNPs with chronic inflammatory conditions, especially respiratory and rheumatoid diseases, were confirmed by several studies (Kato et al., 2000; Renzoni et al., 2000; Brown et al., 2006). Renzoni et al. (2000) found that individuals homozygous for both $+785 \mathrm{C}$ and $+1208 \mathrm{~T}$ alleles of the CXCR2 gene were more susceptible to developing systemic sclerosis.

Although the importance of the polymorphisms in the CXCR2 gene in inflammatory process has been confirmed (Barnes, 1999; Kato et al., 2000; Qiu et al., 2003), it is not known whether these SNPs could also be related to periodontitis. Therefore, the aim of this study was to investigate whether $+785(\mathrm{C} / \mathrm{T})$, $+1208(\mathrm{~T} / \mathrm{C})$, and $+1440(\mathrm{G} / \mathrm{A})$ SNPs in the CXCR2 gene, as well as their haplotypes, are associated with susceptibility to periodontitis in Brazilian individuals.

\section{Materials and Methods}

\section{Selection of subjects}

This study involved individuals from the State of São Paulo in the southeastern region of Brazil. A total of 487 unrelated subjects were recruited from the patient pool of the School of Dentistry at Araraquara, São Paulo State University (UNESP), from November 2004 to May 2007. The study was approved by the Committee for Ethical Affairs of the São Paulo State University (Protocol number 57/04). All volunteers were informed of the aims and methods of this study, and all gave their written consent.

The exclusion criteria for enrolling patients in the study were use of prophylactic antibiotics, chronic usage of antiinflammatory drugs, current pregnancy, ongoing orthodontic therapy, and self-declared history of diseases that influence the immune system, diabetes mellitus, HIV infection, or immunosuppressive chemotherapy (Kim et al., 2009). Each subject was examined by one of two calibrated periodontists, who carried out the periodontal examinations throughout the study period (weighted kappa $=0.74$, considering the probing depth [PD]). The clinical signs and parameters, including PD, clinical attachment loss (CAL), and bleeding on probing, were assessed at six sites around each tooth using a periodontal Williams probe (Trinity, Campo Mourão, Brazil). The subjects were categorized into two groups:

- Control group: subjects exhibiting no sites with CAL and $\mathrm{PD} \geq 3 \mathrm{~mm}$ and no bleeding on probing

- Periodontitis group: subjects exhibiting one or more sites with CAL and PD $\geq 3 \mathrm{~mm}$ and bleeding on probing.

Information on smoking status was obtained using a selfreported questionnaire, and each subject was classified as a "smoker" or "nonsmoker" according to Kornman et al. (1997). Smokers were defined as current smokers, and nonsmokers were subjects who had never smoked or who were former smokers who had quit smoking at least 5 years ago.

\section{Analysis of genetic polymorphisms}

Buccal epithelial cells from the subjects were obtained with $3 \mathrm{~mL}$ of $3 \%$ glucose mouthwash for $2 \mathrm{~min}$. DNA was extracted with a phenol/chloroform/isoamyl alcohol (25:24:1) solution and precipitated with a salt ethanol solution (Sambrook, 2001). The $+785(\mathrm{C} / \mathrm{T}),+1208(\mathrm{~T} / \mathrm{C})$, and +1440 (G/A) SNPs in the CXCR2 gene were examined using the sequence-specific primer-polymerase chain reaction method (SSP-PCR) as previously reported (Renzoni et al., 2000). SSP-PCRs were performed in a $13 \mu \mathrm{L}$ mixture containing $1 \times$ buffer $(20 \mathrm{mM}$ Tris- $\mathrm{HCl}$ and $50 \mathrm{mM} \mathrm{KCl}, \mathrm{pH} 8.4$; Invitrogen, São Paulo, Brazil), $0.2 \mathrm{mM}$ of each dNTP (GE Healthcare Life Sciences, Buckinghamshire, United Kingdom), $2.0 \mathrm{mM} \mathrm{MgCl}_{2}$, $3 \mathrm{U}$ Platinum Taq DNA Polymerase (Invitrogen), and $150 \mathrm{ng}$ of genomic DNA. The polymorphisms were amplified using primer sets and thermocycler conditions according to Renzoni et al. (2000), with some modifications. For the $+1208(\mathrm{~T} / \mathrm{C}) \mathrm{SNP}, 0.2 \mu \mathrm{M}$ of each control APC, forward and reverse primer were used, and the forward primer 5' AGGCTGGCCAACGGGG/A 3' was used for the $+1440(\mathrm{G} / \mathrm{A}) \mathrm{SNP}$, giving a product size of $433 \mathrm{bp}$.

All of the SSP-PCRs were performed in a Mastercycler Gradient thermocycler (Eppendorf, Hamburg, Germany), followed by electrophoresis on a $10 \%$ polyacrylamide gel (USB, Cleveland, $\mathrm{OH}$ ), stained by the silver staining method and photographed using the GDS 8000 System (UVP, Upland, CA).

\section{Statistical analysis}

The illustrative power calculations used to estimate the relevance of the $p$-values produced from this dataset were performed using the methodology for discrete traits in case-control studies (Purcell et al., 2003). The parameters considered were similar to those used by Brett et al. (2005), including the chronic periodontitis prevalence of 0.06 (Dini and Castellanos, 1995).

Differences between the allelic and genotypic frequencies of polymorphisms in the CXCR2 gene in the control and periodontitis groups were analyzed by the two-sided Fisher's exact test or, in case of a rare polymorphism, by the CLUMP program that employs Monte Carlo simulations (Sham and Curtis, 1995). Associations between the polymorphisms and certain characteristics of the subjects (age, sex, skin color, and smoking status) in the control and periodontitis groups were analyzed using the chi-squared test, followed by univariate and multivariate logistic regression modeling. Statistical analyses were performed using the SAS statistical package version 9 (SAS Institute, Cary, NC).

The ARLEQUIN version 3.1 program (Excoffier et al., 2005) was used to calculate Hardy-Weinberg equilibrium, to reconstruct haplotypes by the expectation-maximization algorithm (as the gametic phase is unknown) and to evaluate a likelihood ratio test of linkage disequilibrium. Differences in the haplotype distributions between the studied groups were assessed by the CLUMP program. The relationship between the computationally inferred haplotypes arranged as alleles or genotypes and periodontal disease susceptibility was analyzed by the two-sided Fisher's exact test and by the odds ratio (OR) and 95\% confidence interval (95\% CI) calculations using the GraphPad InStat version 3.05 software (San Diego, CA). In a subgroup analysis, smokers were excluded and 
statistical analyses were performed in nonsmokers as well. The differences were considered significant when $p<0.05$.

\section{Results \\ SNP analysis}

The power calculations performed in this study show that the sample size required to ascertain the significance of an association between periodontal disease and the studied genetic polymorphisms with an alpha value of 0.001 and power of $95 \%$ was 175 individuals. Therefore, the number of subjects enrolled in this study was large enough to detect association with an acceptable level of confidence.

The population investigated here was primarily composed of female subjects $(61.4 \%)$, whites $(58.3 \%)$, and nonsmokers $(83.2 \%)$ (Table 1$)$. The subjects were classified according to their skin color, as proposed by Peres et al. (2007), as whites (predominantly of European heritage), darker-skinned blacks (predominantly African heritage), lighter-skinned blacks (a mixture between European, African, and Amerindian heritages), or yellow (Asian descent) (Table 1).

The control group had an average of $27.6( \pm 2.1)$ teeth remaining, while the periodontitis group had $19.7( \pm 4.3)$ teeth remaining. The number of teeth with PD and CAL $>3 \mathrm{~mm}$ was 0 in the control group and $5.65( \pm 3.6)$ in the periodontitis group.

In the control group, only the genotype distribution of the +1440 SNP (rs1126580) was consistent with the assumption of Hardy-Weinberg equilibrium. Table 2 shows the results of the univariate analysis used to evaluate any association between periodontitis and the age, sex, skin color, smoking status, and genotypic distributions of the patients. Significant associations were observed with age (ORs ranging from 3.66 for age group 30-39 to 29.2 for age group 60-69), skin color $(\mathrm{OR}=1.78$ for lighter-skinned blacks; $\mathrm{OR}=2.57$ for darkerskinned blacks), smoking status $(\mathrm{OR}=3.36)$, the SNP rs1126580 $(\mathrm{OR}=0.4$ for $\mathrm{GG}$ genotype; $\mathrm{OR}=1.605$ for $\mathrm{GA}$ genotype), and periodontitis. Therefore, these characteristics were considered confounding factors of periodontitis. In contrast, neither sex nor the +785 (rs2230054) or +1208

Table 1. Characteristics of the Studied Groups

\begin{tabular}{lccc}
\hline & $\begin{array}{c}\text { Control } \\
(\mathrm{n}=215)\end{array}$ & $\begin{array}{c}\text { Periodontitis } \\
(\mathrm{n}=272)\end{array}$ & $\begin{array}{c}\text { Total } \\
(\mathrm{n}=487)\end{array}$ \\
\hline $\begin{array}{l}\text { Age, mean }( \pm \mathrm{SD}), \\
\text { years }\end{array}$ & $35.3( \pm 10.4)$ & $43.4( \pm 10.5)$ & $39.7( \pm 11.2)$ \\
$\begin{array}{l}\text { Sex, } n(\%) \\
\text { Female }\end{array}$ & $127(59)$ & $172(63.2)$ & $299(61.4)$ \\
$\quad$ Male & $88(41)$ & $100(36.8)$ & $188(38.6)$ \\
$\begin{array}{l}\text { Skin color, } n(\%) \\
\text { White }\end{array}$ & $144(67)$ & $140(51.4)$ & $284(58.3)$ \\
$\begin{array}{l}\text { Darker-skinned } \\
\text { blacks }\end{array}$ & $24(11.2)$ & $60(22)$ & $84(17.2)$ \\
$\begin{array}{l}\text { Lighter-skinned } \\
\text { blacks }\end{array}$ & $41(19)$ & $71(26)$ & $112(23)$ \\
$\begin{array}{l}\text { Yellow } \\
\text { Smoking habits, } n(\%) \\
\quad \text { Nonsmokers }\end{array}$ & $6(2.8)$ & $1(0.6)$ & $7(1.5)$ \\
$\quad$ Smokers & $18(8.4)$ & $64(23.6)$ & $82(16.8)$ \\
\hline
\end{tabular}

(rs1126579) SNPs in the CXCR2 gene were associated with periodontitis (Table 2).

To more accurately evaluate the strength of any association and to eliminate the distortion caused by confounding effects, multivariate analysis was performed. Although sex and the rs2230054 and rs1126579 SNPs were not associated with periodontitis, we included them in the multivariate analysis to adjust for any small confounding effects. Except for the GG genotype of the +1440 SNP (rs1126580), all of the confounding factors detected by univariate analysis were also detected by multivariate analysis (Table 2).

In the univariate analysis, for the $+1440 \mathrm{SNP}$, when comparing the three genotypes, it was observed that the GG genotype was shown to be protective against periodontitis $(\mathrm{OR}=0.4 ; \mathrm{CI}=0.193,0.831)$ (Table 2); when comparing the GG with GA and AA, the GG genotype was also found to be protective against periodontitis $(p=0.0002$; OR $=0.287 ; 95 \%$ $\mathrm{CI}=0.146,0.562)$. Multiple logistic regression analysis confirmed that individuals carrying the GG genotype of the rs1126580 SNP were protected against the development of periodontitis $(\mathrm{OR}=0.423 ; 95 \% \mathrm{CI}=0.187,0.957)$, even after adjusting for covariates, including age, sex, skin color, and smoking status.

Indeed, the data in Table 3, which shows the allele and genotype frequencies of the studied SNPs in different subgroups, demonstrated that the +1440 SNP genotype distribution was significantly different for all subgroups: total $(p<0.0001)$, nonsmokers $(p=0.0002)$, whites $(p=0.0067)$, and white nonsmokers $(p=0.0139)$, where all the OR and CI values indicated the GG genotype as associated with protection against periodontitis. For example, considering a subgroup formed by only white nonsmokers, the +1440 GG showed the $\mathrm{OR}=0.37$ and $95 \% \mathrm{CI}=0.15,0.92$. These significant results in Table 3 are in agreement with the results obtained in the univariate and multivariate analysis (Table 2), in which the GG genotype of the rs1126580 SNP seems to protect individuals against periodontitis.

\section{Haplotype analysis}

In the control and periodontitis groups, linkage disequilibrium was observed among nearly all SNPs $(p=0.00000 \pm 0.00000)$. The exception to this is that linkage disequilibrium was not detected between the rs2230054 and rs1126580 SNPs ( $p=0.34604 \pm 0.0046)$ in the control group.

The distributions of the haplotype sets in the control and periodontitis groups were examined using the CLUMP program. As summarized in Table 4, this analysis revealed a significant difference between the two groups in both the total sample $(p=0.0029)$, nonsmokers and white nonsmokers $(p=0.0009)$. When each haplotype was evaluated for an association with periodontitis in the white nonsmoker subgroup, we observed that individuals carrying the haplotypes TCA $(\mathrm{OR}=1.47 ; 95 \% \mathrm{CI}=1.01,2.14)$ and CCG $(\mathrm{OR}=6.13$; $95 \% \mathrm{CI}=1.32,28.3)$ were more likely to develop periodontitis. The haplotypes CCA $(\mathrm{OR}=0.41 ; 95 \% \mathrm{CI}=0.19,0.87)$ and TCG $(\mathrm{OR}=0.33 ; 95 \% \mathrm{CI}=0.15,0.73)$ appeared to have the opposite effect; that is, these haplotypes seemed to protect individuals against the disease (Table 4).

Computationally obtained maximum-likelihood haplotype frequencies revealed that the distributions of the haplotypes arranged as genotypes (assessed by the CLUMP 


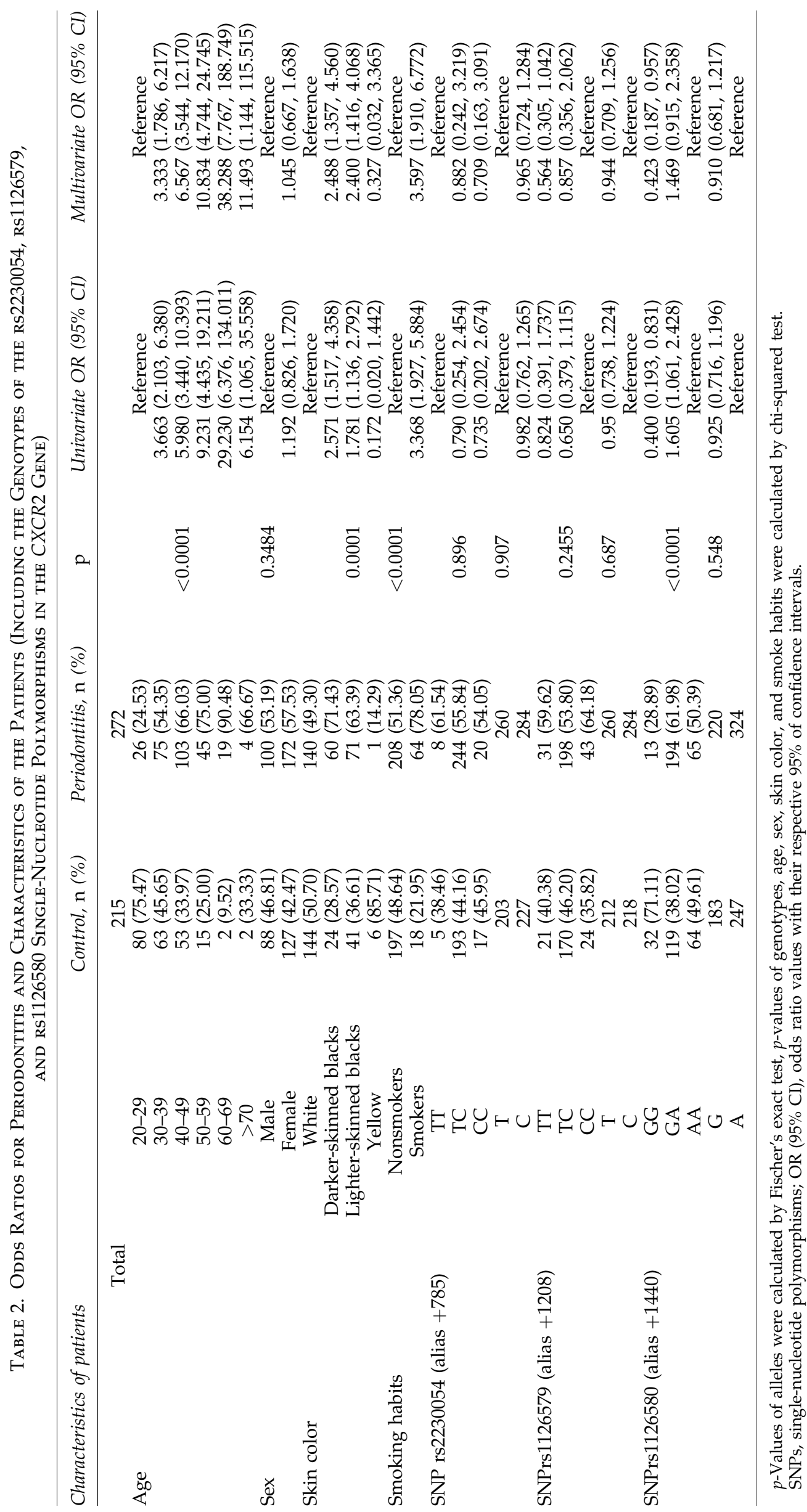




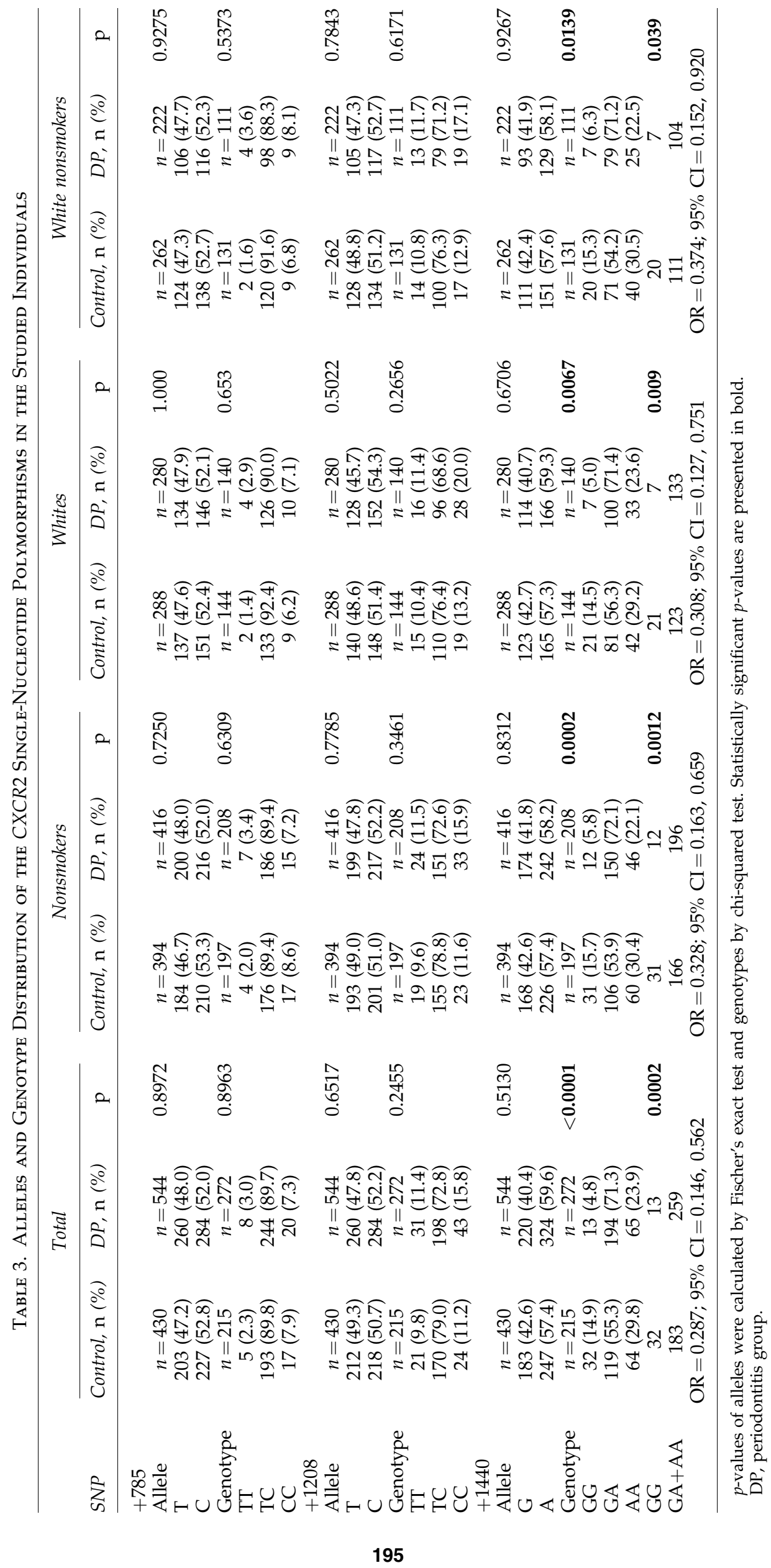




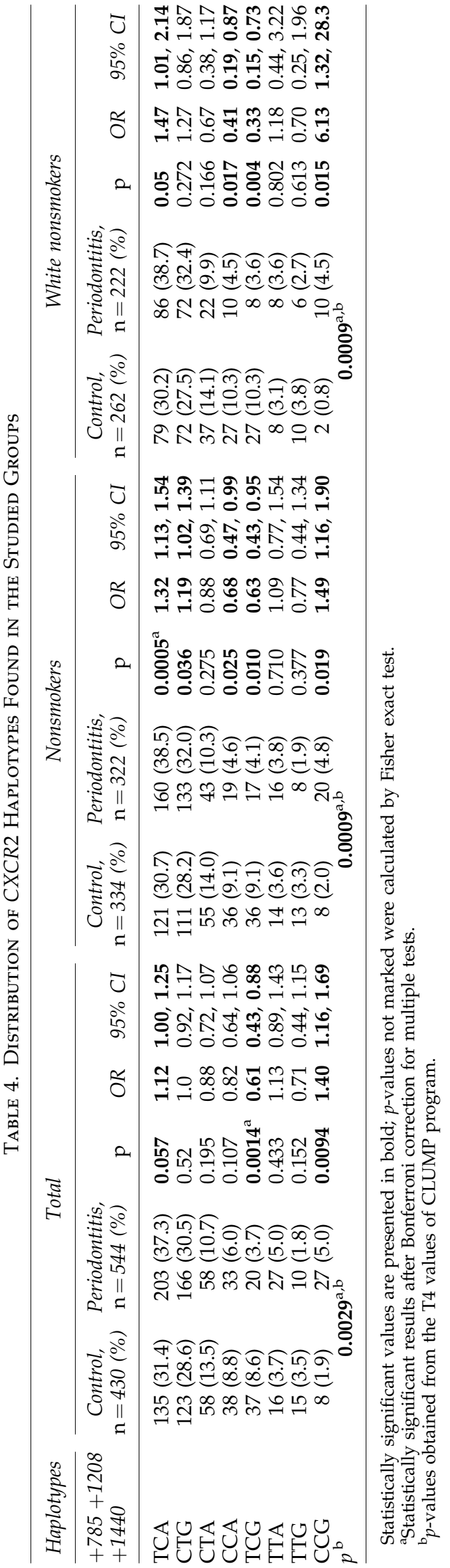

program) were significantly different between the control and periodontitis groups for both the total sample $(p=0.0069)$, nonsmokers $(p=0.0019)$ and white nonsmokers $(p=0.0149)$ (Table 5). Analysis of each haplotype indicated that nonsmokers carrying the CTG/TCA $(\mathrm{OR}=2.08 ; 95 \%$ $\mathrm{CI}=1.24$, 3.51) were more susceptible to the development of periodontitis than individuals carrying other haplotypes. White nonsmokers with the CTG/TCG genotype appeared to be genetically protected against the development of periodontitis (OR $=0.29 ; 95 \% \mathrm{CI}=0.09,0.89)$ (Table 5).

\section{Discussion}

Periodontitis has a complex etiology, as it is primarily caused by bacteria (Van Dyke, 2007), but is also affected by several risk factors, including smoking habits (Grossi et al., 1994), diabetes (Cairo et al., 2001), and genetic polymorphisms (Schenkein, 2002). Previous studies have suggested that inflammatory cytokines also contribute to periodontitis pathogenesis (Page and Schroeder, 1976; Kornman et al., 1997; Graves, 1999). Thus, it is reasonable to assume that genetic variations, such as SNPs, in cytokines and cytokine receptor genes (Breunis et al., 2007) may contribute to susceptibility to periodontitis.

The results presented here revealed that individuals carrying the GA genotype at the +1440 SNP (rs1126580) were protected against the development of periodontitis, even after adjusting for covariates (Table 2). A similar protector effect against the development of Classic Kaposi Sarcoma (Brown et al., 2006) was observed with the presence of both the +1440 G SNP and the +1208T SNP (rs1126579). Classic Kaposi Sarcoma is an inflammatory-mediated disease characterized by localized pathogenesis and involves the expression of proinflammatory cytokines (Miles et al., 1990). The $+1208(\mathrm{~T} / \mathrm{C})$ and $+1440(\mathrm{G} / \mathrm{A})$ genetic variants in the CXCR2 gene are located within the $3^{\prime}$ untranslated region of exon 3 and have the capacity to alter mRNA processing, stability or translation (Ahuja et al., 1994; Sprenger et al., 1994). Functional studies suggest that CXCR2 indirectly activates fibroblasts by mediating the recruitment of $\mathrm{T}$ cells (Santamaria et al., 1996), a process similar to that observed both in Kaposi Sarcoma spindle cell transformation (Brown et al., 2006) and in periodontitis (Van Dyke, 2007). Unfortunately, studies investigating the functionality of polymorphisms in the CXCR2 gene have not been performed. It is unclear, for example, whether a polymorphism in this gene could influence the expression level of the CXCR-2 protein or whether an SNP could modify the capacity of the receptor to bind to IL-8.

The excess heterozygotes relative to the expected number of heterozygotes for all SNPs may explain why HardyWeinberg equilibrium of the genotype distributions in our study was not observed. Indeed, high heterozygosity was previously observed when approximately $50 \%$ of the individuals were genotyped for the +1440 SNP by the PCRrestriction fragment length polymorphism method (Viana et al., 2007). Errors in genotyping are commonly used to explain departures from Hardy-Weinberg equilibrium. In this study, however, we believe that this is not a strong possibility because when a sample demonstrated an uncertain pattern of bands, it was repeated until an accurate genotype could be obtained. Another possible explanation 


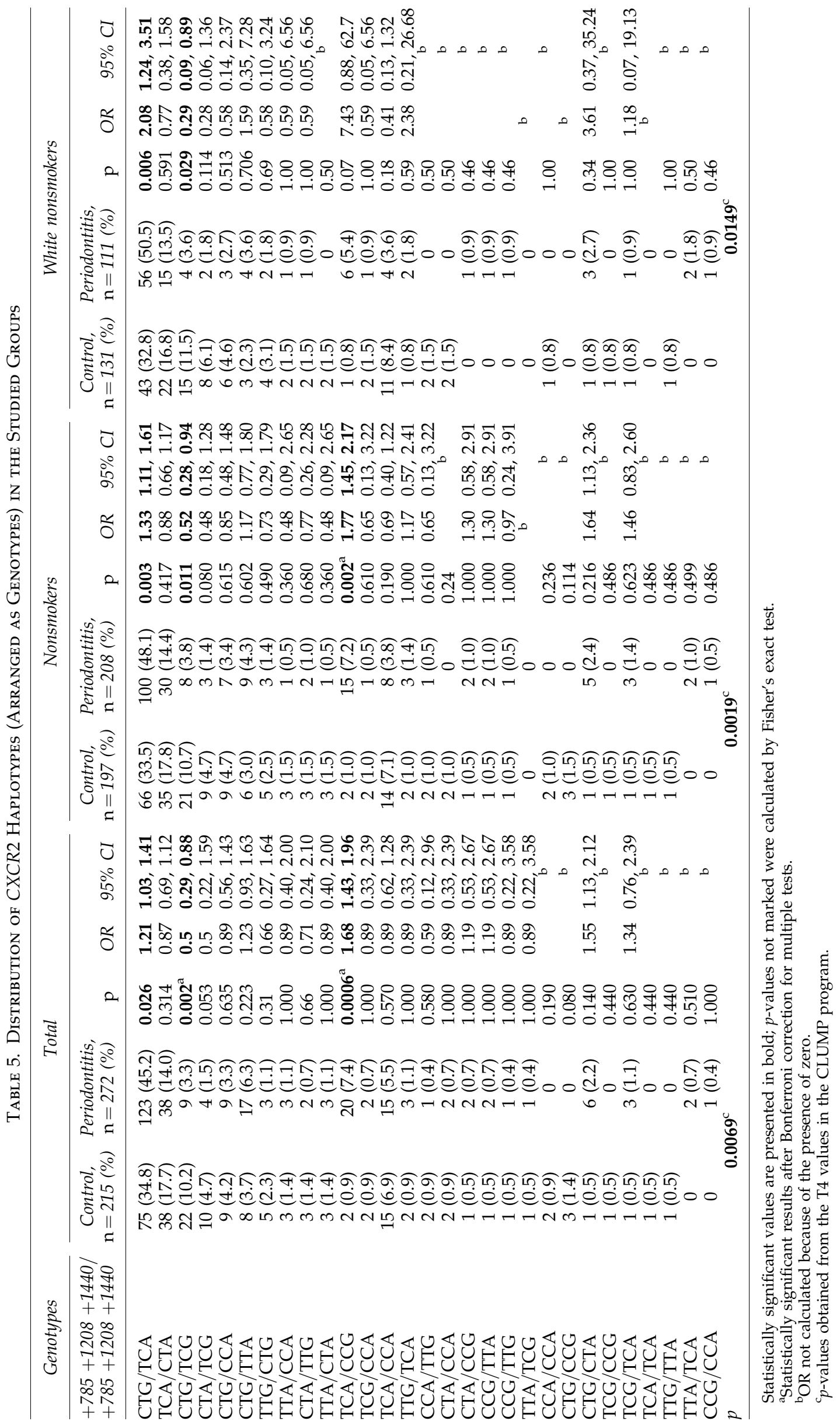


for the departures from Hardy-Weinberg equilibrium is the selection criteria used for patients with periodontitis. Similar findings were obtained in a study focusing on aggressive periodontitis and the -590 and -34 SNPs in the IL4 gene (Gonzales et al., 2007).

When the three SNPs were analyzed together as haplotypes, we found a significant association between the haplotypes and periodontitis susceptibility (Tables 4 and 5). Similar findings were observed with the same population in a previous study (Kim et al., 2009) and in other studies of Brazilian individuals in which IL10 (Scarel-Caminaga et al., 2004) and a vitamin D receptor (de Brito Junior et al., 2004) were examined. These previous studies corroborate the idea that haplotypes are more powerful in detecting susceptibility alleles than individual polymorphisms and that they may give more information on the disease.

To evaluate any potential confounding effects that could cause bias in this association study of periodontitis, important factors known to influence the pathogenesis of periodontitis were assessed by univariate and multivariate analysis. The univariate analysis showed that age, skin color, and smoking status were associated with periodontitis (Table 2). These findings were also obtained in the multivariate analysis. Similar results were also obtained in a previous study investigating the association of a polymorphism in the IL8 gene with periodontitis in the same population (Kim et al., 2009). It has been established that smoking habits are an important risk factor for the initiation and progression of periodontitis (Genco, 1996; Kornman, 2005; Gonzales et al., 2007). Kornman et al. (1997) suggested that the smoking-related risk could often obscure the polymorphism-related risk. In the present study, smoking status was a confounding factor of periodontitis $(p<$ 0.0001 ) (Table 2). The results of the genetic analyses of the total sample were not notably different from those obtained for nonsmokers only (Tables 3-5). A possible reason for this could be the low frequency of smokers $(16.8 \%)$ in the total sample. Nevertheless, because others and we have found an association of smoking habits with periodontitis $\left(\mathrm{OR}_{\text {adjusted }}=3.597 ; 95 \% \mathrm{CI}=1.910,6.772\right.$; Table 2$)$, we performed the haplotype analysis without smokers. Without the influence of smoking habits, results of the haplotype analyses showed significant results (Tables 4 and 5). Further, to eliminate as many confounding factors as possible, that is, skin color and smoking habits, all the statistical analyses were performed, including only white individuals who were nonsmokers (Tables 3-5). For white nonsmokers it was found that the CTG/TCA is associated with a genetic predisposition to periodontitis and that the CTG/TCG genotype is associated with protection against periodontitis (Table 5).

These results, however, could be influenced by age. The increase of age has been associated with the prevalence, extent, and severity of periodontitis (Heitz-Mayfield, 2005). It has also been proposed that the increased level of periodontal destruction observed with aging is a result of cumulative destruction rather than increased rates of destruction (Genco, 1996). Therefore, for multivariate analysis to completely eliminate the effect of age on the studied population, the mean age of the subjects should have been similar. Thus, the mean age difference between groups may be a limitation of the present study.
The analysis of haplotypes arranged as alleles revealed a significant difference between their distributions in the control and periodontitis groups, where the TCA and CCG haplotypes were associated with susceptibility to periodontitis and the CCA and TCG haplotypes were associated with protection against the development of periodontitis (Table 4). In the literature, the only study that investigated the same SNPs in the CXCR2 gene was conducted in a Chinese population. That study found five prevalent haplotypes, with the CTG haplotype being the most predominant, followed by the TCA haplotype (23\%) (Hsing et al., 2008). In the Brazilian population studied here, eight haplotypes were found; three of these haplotypes (CTA, TTA, and TTG) were identified for the first time in this study. Interestingly, the most common haplotype in the Chinese population, CTG (64.4\% for controls), was much less common in the Brazilian population $(28.6 \%$ for total controls, Table 4$)$ and was associated with susceptibility to periodontitis in Brazilian nonsmokers. The CCA haplotype, which was associated with protection against the development of periodontitis in nonsmokers, was seven times more frequent in Brazilian population $(8.8 \%)$ than in the Chinese population $(1.2 \%$, the rarest haplotype observed by Hsing et al., 2008).

Because the significant results of the CXCR2 gene association with periodontitis were obtained in a Brazilian admixture population, additional studies enrolling other ethnically diverse populations must be performed to ascertain whether this gene could be a marker for periodontitis or other diseases, such as inflammatory diseases. Also, to better understand the results of the association-disease studies, additional studies investigating the functionality of the CXCR2 polymorphisms will be necessary.

In conclusion, to our knowledge, our findings are the first to indicate an association between the +1440 SNP and haplotypes in the CXCR2 gene with susceptibility to or protection against periodontitis in Brazilian individuals.

\section{Acknowledgments}

This study was supported by the Foundation for Research Support of the State of São Paulo-FAPESP, Grants 2003/10424-0 and 2005/03231-7.

\section{Disclosure Statement}

No competing financial interests exist.

\section{References}

Ahuja, S.K., Shetty, A., Tiffany, H.L., and Murphy, P.M. (1994). Comparison of the genomic organization and promoter function for human interleukin-8 receptors A and B. J Biol Chem 269, 26381-26389.

Baggiolini, M. (1998). Chemokines and leukocyte traffic. Nature 392, 565-568.

Barnes, P.J. (1999). Genetics and pulmonary medicine: 9. Molecular genetics of chronic obstructive pulmonary disease. Thorax 54, 245-252.

Brett, P.M., Zygogianni, P., Griffiths, G.S., Tomaz, M., Parkar, M., D'Aiuto, F., and Tonetti, M. (2005). Functional gene polymorphisms in aggressive and chronic periodontitis. J Dent Res 84, 1149-1153.

Breunis, W.B., Biezeveld, M.H., Geissler, J., Kuipers, I.M., Lam, J., Ottenkamp, J., Hutchinson, A., Welch, R., Chanock, S.J., and 
Kuijpers, T.W. (2007). Polymorphisms in chemokine receptor genes and susceptibility to Kawasaki disease. Clin Exp Immunol 150, 83-90.

Brown, E.E., Fallin, D., Ruczinski, I., Hutchinson, A., Saats, B., Vitale, F., Lauria, C., Serraino, D., Rezza, G., Mbisa, G., Whitby, D., Messina, A., Goedert, J.J., and Chanock, S.J. (2006). Associations of classic Kaposi sarcoma with common variants in genes that modulate host immunity. Cancer Epidemiol Biomarkers Prev 15, 928-934.

Cairo, F., Rotundo, R., Frazzingaro, G., Muzzi, L., and Pini Prato, G.P. (2001). Diabetes mellitus as a risk factor for periodontitis. Minerva Stomatol 50, 321-330.

Campa, D., Hung, R.J., Mates, D., Zaridze, D., SzeszeniaDabrowska, N., Rudnai, P., Lissowska, J., Fabiánová, E., Bencko, V., Foretova, L., Janout, V., Boffetta, P., Brennan, P., and Canzian, F. (2005). Lack of association between -251 T $>A$ polymorphism of IL8 and lung cancer risk. Cancer Epidemiol Biomarkers Prev 14, 2457-2458.

de Brito Junior, R.B., Scarel-Caminaga, R.M., Trevilatto, P.C., de Souza, A.P., and Barros, S.P. (2004). Polymorphisms in the vitamin $\mathrm{D}$ receptor gene are associated with periodontal disease. J Periodontol 75, 1090-1095.

Dini, E.L., and Castellanos, R.A. (1995). CPITN: time and cost estimates for periodontal prevention and treatment procedures. Braz Dent J 6, 53-58.

Excoffier, L., Laval, G., and Schneider, S. (2005). Arlequin (version 3.0): an integrated software package for population genetics data analysis. Evol Bioinform Online 1, 47-50.

Genco, R.J. (1996). Current view of risk factors for periodontal diseases. J Periodontol 67, 1041-1049.

Gonzales, J.R., Mann, M., Stelzig, J., Bodeker, R.H., and Meyle, J. (2007). Single-nucleotide polymorphisms in the IL-4 and IL-13 promoter region in aggressive periodontitis. J Clin Periodontol 34, 473-479.

Graves, D.T. (1999). The potential role of chemokines and inflammatory cytokines in periodontal disease progression. Clin Infect Dis 28, 482-490.

Grossi, S.G., Zambon, J.J., Ho, A.W., Koch, G., Dunford, R.G., Machtei, E.E., Norderyd, O.M., and Genco, R.J. (1994). Assessment of risk for periodontal disease. I. Risk indicators for attachment loss. J Periodontol 65, 260-267.

Hafajee, A.D., and Socransky, S.S. (1994). Microbial etiological agents of destructive periodontal diseases. Periodontol 2000 5, 78-111.

Heitz-Mayfield, L.J.A. (2005). Disease progression: identification of high-risk groups and individuals for periodontitis. I Clin Periodontol 32, 196-209.

Hsing, A.W., Sakoda, L.C., Rashid, A., Andreotti, G., Chen, J., Wang, B.S., Shen, M.C., Chen, B.E., Rosenberg, P.S., Zhang, M., Niwa, S., Chu, L., Welch, R., Yeager, M., Fraumeni, J.F., Jr., Gao, Y.T., and Chanock, S.J. (2008). Variants in inflammation genes and the risk of biliary tract cancers and stones: a population-based study in China. Cancer Res 15, 64426452.

Irwin, C.R., and Myrillas, T.T. (1998). The role of IL-6 in the pathogenesis of periodontal disease. Bucal Dis 4, 43-47.

Kato, H., Tsuchiya, N., and Tokunaga, K. (2000). Single nucleotide polymorphisms in the coding regions of human $\mathrm{CXC}$ chemokine receptors CXCR1, CXCR2 and CXCR3. Genes Immun 1, 330-337.

Kim, Y.J., Viana, A.C., Curtis, K.M., Orrico, S.R., Cirelli, J.A., and Scarel-Caminaga, R.M. (2009). Lack of association of a functional polymorphism in the interleukin 8 gene with susceptibility to periodontitis. DNA Cell Biol 4, 185-190.
Kornman, K.S. (2005). Diagnostic and prognostic tests for oral diseases: practical applications. J Dent Educ 69, 498-508.

Kornman, K.S., Page, R.C., and Tonetti, M.S. (1997). The host response to the microbial challenge in periodontitis: assembling the players. Periodontol 2000 14, 33-53.

Massada, M.P., Person, R., Kenny, J.S., Lee, S.W., Page, R.C., and Allison, A.C. (1990). Measurement of interleukin-1 alpha and 1-beta in gingival crevicular fluid: implications for the pathogeneses of periodontal disease. J Periodontal Res 25, 156163.

Miles, A.S., Rezai, A.R., Salazar-Gonzales, J.F., Vander Meyden, M., Stevens, R.H., Logan, D.M., Mitsuyasu, R.T., Taga, T., Hirano, T., Kishimoto, T., and Martínez-Maza, O. (1990). AIDS Kaposi sarcoma-derived cells produce and respond to interleukin 6. Proc Natl Acad Sci USA 87, 4068-4072.

Morris, S.W., Nelson, N., Valentine, M.B., Shapiro, D.N., Look, A.T., Kozlosky, C.J., Beckmann, M.P., and Cerretti, D.P. (1992). Assignment of genes encoding human interleukin-8 receptor types 1 and 2 and an interleukin- 8 receptor pseudogene to chromosome 2q35. Genomics 14, 685-691.

Mukaida, N. (2003). Pathophysiological roles of interleukin-8/ CXCL8 in pulmonary diseases. Am J Physiol Lung Cell Mol Physiol 284, L566-L577.

Murphy, P.M., and Tiffany, H.L. (1991). Cloning of complementary DNA encoding a functional human interleukin-8 receptor. Science 253, 1280-1283.

Ozawa, A., Tada, H., Tamai, R., Uehara, A., Watanabe, K., Yamaguchi, T., Shimauchi, H., Takada, H., and Sugawara, S. (2003). Expression of IL-2 receptor and chains by human gingival fibroblasts and up-regulation of adhesion to neutrophils in response to IL-2. J Leuk Biol 74, 352-359.

Page, R.C., and Schroeder, H.E. (1976). Pathogenesis of inflammatory periodontal disease. A summary of current work. $\underline{\text { Lab }}$ Invest 34, 235-249.

Peres, M.A., Antunes, J.L., Boing, A.F., Peres, K.G., and Bastos, J.L. (2007). Skin colour is associated with periodontal disease in Brazilian adults: a population-based oral health survey. J Clin Periodontol 34, 196-201.

Purcell, S., Cherny, S.S., and Sham, P.C. (2003). Genetic Power Calculator: design of linkage and association genetic mapping studies of complex traits. Bioinformatics 19, 149-150.

Qiu, Y., Zhu, J., Bandi, V., Atmar, R.L., Hattotuwa, K., Guntupalli, K.K., and Jeffery, P.K. (2003). Biopsy neutrophilia, neutrophil chemokine and receptor gene expression in severe exacerbations of chronic obstructive pulmonary disease. Am J Respir Crit Care Med 168, 968-975.

Renzoni, E., Lympany, P., Sestini, P., Pantelidis, P., Wells, A., Black, C., Welsh, K., Bunn, C., Knight, C., Foley, P., and du Bois, R.M. (2000). Distribution of novel polymorphisms of the interleukin- 8 and CXC receptor 1 and 2 genes in systemic sclerosis and crytogenic fibrosing alveolitis. Arthritis Rheum 43, 1633-1640.

Sambrook, J.R.D. (2001). Molecular Cloning: A Laboratory Manual, 3rd edition (Cold Spring Harbor Laboratory Press, Cold Spring Harbor).

Santamaria Babi, L.F., Moser, B., Perez Soler, M.T., Moser, R., Loetscher, P., Villiger, B., Blaser, K., and Hauser, C. (1996). The interleukin- 8 receptor $\mathrm{B}$ and $\mathrm{CXC}$ chemokines can mediate transendothelial migration of human skin homing T cells. Eur J Immunol 26, 2056-2061.

Scarel-Caminaga, R.M., Trevilatto, P.C., Souza, A.P., Brito, R.B., Camargo, L.E., and Line, S.R. (2004). Interleukin 10 gene promoter polymorphisms are associated with chronic periodontitis. J Clin Periodontol 31, 443-448. 
Schenkein, H.A. (2002). Finding genetic risk factors for periodontal diseases: is the climb worth the view? Periodontol 2000 30, 79-90.

Sham, P.C., and Curtis, D. (1995). Monte Carlo tests for associations between disease and alleles at highly polymorphic loci. Ann Hum Genet 59, 97-105.

Sprenger, H., Lloyd, A.R., Lautens, L.L., Bonner, T.I., and Kelvin, D.J. (1994). Structure, genomic organization, and expression of the human interleukin-8 receptor B gene. J Biol Chem 269, 11065-11072.

Strieter, R.M. (2002). Interleukin-8: a very important chemokine of the human airway epithelium. Am J Physiol Lung Cell Mol Physiol 283, L688-L689.

Susin, C., Valle, P., Opperman, R.V., Haugejorden, O., and Albandar, J.M. (2005). Occurrence and risk indicators of increased probing depth in an adult Brazilian population. J Clin Periodontol 32, 123-129.

Van Dyke, T.E. (2007). Cellular and molecular susceptibility determinants for periodontitis. Periodontol 2000 45, 10-13.

Viana, A.C., Kim, Y.J., Cirelli, J.A., Orrico, S.P., Curtis, K.C., Cano, V.P., Valentini, S.R., and Scarel-Caminaga, R.M. (2007). A novel PCR-RFLP assay for the detection of the single nucleotide polymorphism at position +1440 in the human CXCR2 gene. Biochem Genet 45, 737-741.
Yamazaki, K., Nakajima, T., Gemmel, E., Polak, B., Seymor, G.J., and Hara, K. (1994). IL-4 and IL-6 producing cells in human periodontal disease tissue. J Oral Pathol Med 23, 347353.

Yamazaki, K., Nakajima, T., Kubota, Y., Gemmell, E., Seymor, G.J., and Hara, K. (1997). Cytokine messenger RNA expression in chronic inflammatory periodontal disease. Oral Microbiol Immunol 12, 281-287.

Yoshie, H., Kobayashi, T., Tai, H., and Galicia, J.C. (2007). The role of genetic polymorphisms in periodontitis. Periodontol $200043,102-132$.

Address correspondence to: Raquel M. Scarel-Caminaga, Ph.D. Department of Morphology School of Dentistry at Araraquara UNESP-São Paulo State University, CP 331 Araraquara CEP 14801-903, SP Brazil

E-mail: raquel@foar.unesp.br

Received for publication May 14, 2009; received in revised form October 6, 2009; accepted October 7, 2009. 
This article has been cited by:

1. Vibha Singh, Praveen Kumar Jaiswal, Poonam Tiwari, Rakesh Kapoor, Rama Devi Mittal. 2013. Association of chemokine gene variants with end stage renal disease in North Indian population. Transplant Immunology 28:4, 189-192. [CrossRef]

2. Raquel M Scarel-Caminaga, Karen MC Curtis, Rivelto Renzi, Patricia M Sogumo, Giovana Anovazzi, Aline C Viana, Yeon J Kim, Silvana RP Orrico, Joni A Cirelli. 2011. Variation in the CXCR1 gene (IL8RA) is not associated with susceptibility to chronic periodontitis. Journal of Negative Results in BioMedicine 10:1, 14. [CrossRef] 